\title{
"Bolivia no tiene mejor amigo que Chile, ni peor verdugo que el Perú": Dos cartas de Justiniano Sotomayor a Hilarión Daza, abril de 1879
}

\section{Patricio Ibarra Cifuentes ${ }^{1}$}

La ocupación por parte de tropas chilenas del puerto de Antofagasta, el 14 de febrero de 1879, significó el quiebre definitivo en la relación de Chile y Bolivia y el inicio de las hostilidades que desembocarían en el estallido de la Guerra del Pacífico, conflicto que se desarrollaría hasta 1884 y cuyas consecuencias han dejado una huella imborrable en los países beligerantes y repercuten hasta nuestros días.

El casus belli del conflicto, el intento de remate de las instalaciones de la Compañía de Salitres y Ferrocarril de Antofagasta por parte del gobierno boliviano encabezado por Hilarión Daza, y producto de la negativa de la empresa de capitales chilenos y británicos de pagar un impuesto adicional de diez centavos por cada quintal de nitrato exportado, provocó la airada reacción de la administración chilena del presidente Aníbal Pinto, que envió tropas en pie de guerra para evitar, irrumpiendo y ocupando por la fuerza territorio a la sazón de Bolivia, lo que a su juicio era la violación flagrante del tratado de límites suscrito entre La Moneda y el Palacio Quemado en $1874 .{ }^{2}$ Como se sabe, el conflicto armado se materializó a muy poco andar, pues Bolivia declaró la guerra a Chile el $1^{\circ}$ de marzo de 1879, arrastrando también al Perú, que se hallaba unido a la nación altiplánica por un Tratado de Alianza Defensiva secreto, vigente desde junio de 1873. Develado el pacto entre los gobiernos peruano y boliviano, Chile comenzó a su vez las hostilidades contra el Perú el 5 de abril.

Chileno. Doctor en Historia. Centro de Estudios Históricos, Universidad Bernardo O'Higgins. Este trabajo es resultado de la investigación realizada en el marco del Proyecto FONDECYT № 11160136 "La guerra íntima: testimonios, experiencias y cotidianidad en la Guerra del Pacífico (1879-1883)". E-mail: patricio.ibarra@ubo.cl

2 El tratado del 6 de agosto de 1874, firmado por los presidentes Federico Errázuriz y Mariano Baptista estableció: "Los derechos de exportación que se impongan sobre los minerales exportados en la zona de terreno de que hablan los artículos precedentes, no excederán la cuota de la que actualmente se cobra, y las personas, industrias y capitales chilenos no quedarán sujetos a más contribuciones de cualquiera clase que sean que las que al presente existen. La estipulación contenida en este artículo durará por el término de veinticinco años". (Ahumada I, 1884: 7). 
Sin embargo, ante la irrupción del Perú en la escena como mediador primero, misión Lavalle mediante, y como beligerante después al lado de Bolivia, las autoridades de La Moneda intentaron, en varias oportunidades y a través de distintos métodos, atraer a las del Palacio Quemado para separarla de su alianza con la nación incaica. Esto es lo que se conoce en la historiografía chilena como la "Política boliviana", desarrollada con entusiasmo desde Santiago, en especial desde el despacho del ministro y futuro presidente Domingo Santa María. ${ }^{3}$ Una de las primeras manifestaciones de ella, fueron las cartas enviadas por Justiniano Sotomayor, ex cónsul chileno en Bolivia, a Hilarión Daza. La primera de ellas fue mandada el 8 de abril y la segunda el 11 del mismo mes, es decir, pocos días después de la declaración de guerra de Chile al Perú.

Se trató de una invitación abierta a Bolivia a romper la alianza con el Perú, a muy poco tiempo de develada al gran público la existencia del tratado de alianza defensiva que unía a ambos países desde 1873 y, más importante aún, de las hostilidades que desembocaron en la declaración de la guerra, olvidando que la contienda se había iniciado por la disputa entre chilenos y bolivianos por las salitreras de Antofagasta. El incentivo para que Daza renunciara a su pacto con los peruanos era la entrega por parte de Chile del puerto de Arica, dando por sentado que, tras la campaña militar que pronto se iniciaría, en el mar y en tierra, los chilenos quedarían en completa posesión de Tarapacá merced a la superioridad de sus armas. Del mismo modo, Sotomayor argumentó a Daza que Chile era un mejor aliado para Bolivia y que, por lo tanto, sería una relación mucho más fructífera y conveniente para ella, pues "es el único país que puede librar a Bolivia del pesado yugo con que el Perú la oprime". En su mirada, y sin importar el resultado de la guerra, la nación altiplánica estaría siempre sometida a los intereses del Perú, mientras que al lado de los chilenos podría obtener ganancias mejores e inmediatas asegurando de ese modo su progreso futuro. Aquello dio pie para que Sotomayor asegurara al primer mandatario boliviano que "Bolivia no tiene mejor amigo que Chile, ni peor verdugo que el Perú".

De ese modo, Divide et impera fue la idea que motivó la "Política boliviana" durante la Guerra del Pacífico, asumiendo el gobierno chileno, desde el

\footnotetext{
A lo largo de los tres volúmenes de la Guerra del Pacífico, Gonzalo Bulnes se hace cargo en varias oportunidades de lo que él denomino como la "Política boliviana", la cual estaba destinada a sacar a Bolivia de la alianza con el Perú a través de concesiones territoriales, específicamente de la entrega de Tacna y Arica. En efecto, esta se materializó en distintos momentos del conflicto y a través de diversos medios, entre los cuales se contó la utilización de prisioneros de guerra como emisarios ante las autoridades altiplánicas, entre otros métodos. Todos ellos fracasaron. Su más fervoroso partidario fue Domingo Santa María, ministro de la administración del presidente Aníbal Pinto y futuro mandatario entre 1881 y 1886. Véase Bulnes, 1955.
} 
inicio de las hostilidades, que el verdadero adversario a derrotar era el Perú, intentado someterlo e imponer sus intereses en el conflicto por hacerse del control efectivo de los territorios salitreros de Antofagasta y Tarapacá, ofreciendo una recompensa a Bolivia. Así, Chile accedería a los recursos económicos derivados de la explotación de las materias primas y a una posición de poder en el concierto sudamericano, en concordancia con los principios políticos y de acción diplomática de la época (Tapia, 2016: 134). Ambas misivas constituyeron una apuesta atrevida y a la vez un ejercicio pragmático de política internacional, con el objeto de implementar su política de poder para así resguardar los intereses del momento, imponerse en la guerra que se iniciaba y neutralizar posibles amenazas posteriores (Rubilar, 2004).

Por otra parte, con claridad meridiana, Sotomayor anticipó las consecuencias que tendría para Bolivia el ser derrotada en la guerra que recién se iniciaba, vale decir, perder Antofagasta y toda salida con soberanía al mar. Al respecto, Sotomayor afirmó que, luego del triunfo militar, "Obligaremos al Perú a hacer la paz bajo las condiciones que Chile quiera imponerle y entonces quedará Bolivia imposibilitada para recuperar su antiguo litoral y aun para pensar en conquistar jamás a Tacna, Arica, llo y Moquegua que es y debe ser su sueño dorado de nación". Fue lo que efectivamente ocurrió al finalizar el conflicto.

En menos de dos años los chilenos fueron capaces de conquistar Antofagasta, Tarapacá, Moquegua y Lima. Pese a que la guerra se extendió dos años más después de la entrada de las tropas chilenas a la "Ciudad de los Reyes" (enero de 1881), merced a una enconada pero inútil resistencia a la ocupación desplegada desde la Sierra, el Perú terminó aceptando la cesión a perpetuidad de la rica provincia salitrera de Tarapacá, condición sine qua non exigida por Chile para firmar la paz.. ${ }^{4}$ Por su parte, Bolivia perdió para siempre Antofagasta, región abundante en nitrato y otros minerales no metálicos, donde en 1915 se descubriría en las cercanías de Calama el gran mineral de

4 Esta condición fue exigida en todas las tratativas de paz de la guerra. La primera de ellas, la denominadas "Conferencias de Arica", fueron las conversaciones de paz entre representantes chilenos y aliados desarrolladas a bordo de la corbeta estadounidense Lackawanna, entre el 20 y el 27 de octubre de 1880. El intento de finalizar con la guerra fracasó en tanto los plenipotenciarios del Perú y Bolivia no aceptaron las exigencias de Chile. A saber, 1. Cesión de la provincia de Tarapacá y la faja costera entre Antofagasta y Cobija; 2. Pago de una compensación de guerra por 20 millones de pesos; 3. Devolución de las propiedades confiscadas por el Perú y Bolivia a ciudadanos chilenos; 4. Devolución del transporte Rímac; 5. Anulación del tratado secreto de 1873 firmado por Perú y Bolivia; 6. Ocupación por parte de Chile de Moquegua, Tacna y Arica hasta el cumplimiento de las condiciones recién enumeradas y 7 . Obligación del Perú de no establecer en Arica una plaza fortificada. Finalmente, el Tratado de Ancón estableció en lo sustancial la cesión perpetua de Tarapacá y el mecanismo para la zanjar el dominio futuro de Tacna y Arica que continuarían bajo la administración chilena al menos por diez años (Bulnes II, 1955: 236-259; III: 277-279). 
Chuquicamata, que poseía formidables reservas de cobre. Con todo, tras el fin de las hostilidades y la inapelable derrota militar aliada, en 1895 Tacna y Arica fueron ofrecidas nuevamente a Bolivia en caso que estas quedaran en manos de Chile, tras el plebiscito que debía realizarse para zanjar la posesión de la zona. Aquello provocó la protesta del Perú. Sin embargo, el pacto entre Chile y Bolivia que consideró la cesión de Tacna y Arica fracasó (Gonzalez, 2008: 38-39). De ese modo, la nación altiplánica dejó de poseer una salida soberana al mar, aunque el Tratado de Paz y Amistad de 1904 aseguró por medio de un ferrocarril el acceso al océano Pacífico, a través, paradójicamente, del propio puerto de Arica que se encontraba bajo la soberanía chilena desde junio de $1880 .^{5}$

En una interpretación más amplia, el tenor de las cartas es concordante con la opinión generalizada en la elite política chilena contemporánea, relacionada con que el verdadero adversario de Chile en el conflicto que se iniciaba era el Perú, país al que se le imputaba estar muy interesado en controlar la totalidad del por entonces pingüe negocio salitrero. De esa misma manera, entre los personeros vinculados a la función pública al momento del estallido de la Guerra del Pacífico, se entendía que la obtención y posesión de la provincia de Tarapacá era fundamental para los intereses de Chile durante el desarrollo del conflicto, debido a que se constituiría en una importante fuente de financiamiento para los fuertes gastos que implicaría la campaña militar. ${ }^{6}$ Más importante aún, el floreciente negocio del salitre se consideró como un importante potencial de desarrollo económico futuro, en vista de la crisis económica por la que el país atravesaba en esos momentos, además del agotamiento del ciclo de la plata y de la exportación triguera (Cariola y Sunkel, 1983: 38 y ss.).

Las cartas de Sotomayor no tuvieron el éxito esperado. Daza no dio señales de responder en ningún sentido y, más aún, facilitó los documentos a los periódicos de los países aliados para que fueran publicados. Empero, aquello no significó que en Chile se dieran por terminadas las tratativas para separar a Bolivia del Perú, por cuanto el gobierno continuó insistiendo a través de nuevas misivas que fueron hechas llegar al mandatario altiplánico, esta vez por medio de un ciudadano boliviano de nombre Luis Salinas Vega que residía en Santiago. En esa oportunidad, Daza hizo la pantomima de iniciar un acercamiento con Chile. En efecto, Domingo Santa María, creyendo que la iniciativa tenía posibilidades de llegar a buen puerto, designó a Eusebio Lillo

Véase el artículo $3^{\circ}$ del Tratado de Paz y Amistad de 1904 (Ríos, 1963: 225-226).

Un ejemplo del pensamiento de la elite chilena al respecto son las cartas enviadas por José Francisco Vergara a su hijo José Salvador, fechadas entre los meses de enero y marzo de 1879. Véase "Selección de cartas de José Francisco Vergara sobre la Guerra del Pacífico" (Henríquez, 2009: 225 y ss.). 
como representante oficial para negociar y formalizar un eventual acuerdo (Barros, 1970: 395). Con todo, era muy difícil que Daza u otro gobernante aceptara la propuesta chilena, en tanto Antofagasta le había sido arrebatada en febrero, y ya se había librado un combate en Calama entre tropas chilenas y bolivianas (23 de marzo de 1879). Más aún, la fiebre guerrera se apoderaba de la opinión pública de los países beligerantes.

La idea de la cesión por parte del gobierno chileno de Arica a Bolivia, en el caso que esta nación abandonara la alianza con el Perú, materializada en las cartas de Justiniano Sotomayor aquí trascritas, se conoció y debatió en la prensa chilena. Un ejemplo, es el comentario hecho por el corresponsal en campaña de El Mercurio de Valparaíso, Eloy Caviedes, escrito a inicios del mes de mayo de 1879 a bordo del blindado Blanco Encalada, cuando señaló que la nación altiplánica difícilmente aceptaría Arica sin la posesión al unísono de Mollendo, este último, "comunicado por vía férrea con el interior, puede decirse que forma parte de los límites naturales del litoral boliviano". Tras ello, el cronista mercurial, al meditar respecto de la decidida negativa de Bolivia a aceptar la propuesta, se preguntó si "¿comprenderán su verdadero interés los testarudos de La Paz?" (Castagneto, 2014: 97).

Algo similar ocurrió en Bolivia. El Diario de la campaña del Ejército boliviano, llevado por el destacado intelectual José Vicente Ochoa, a la sazón enlistado como oficial en la hueste de su país, consignó en su anotación del 20 de abril la llegada de la primera carta de Sotomayor a Daza. Al respecto, Ochoa aseguró contento que "los chilenos se ven en un círculo de hierro y ya buscan medios de intrigar la Alianza". Asimismo, anotó que el Dictador, "con la hidalguía que le corresponde", señaló que las haría publicar e informaría a la brevedad de su contenido al presidente del Perú Mariano Ignacio Prado (Ochoa, 1899: 13). Diez días más tarde consignó el arribo de la segunda misiva, exclamando respecto de ella que "Ah! los marcachifles (sic) de Chile" (Ochoa, 1899: 20). Análogo fue lo que se escribió en el folleto intitulado Lo que es Chile y lo que debe hacerse con Chile, escrito por "Un orureño" en abril de 1879 y publicado en La Paz, donde se calificó el envío de ambas esquelas como el ejemplo de la conducta "más pérfida y más inicua", aseverando luego que "solo Chile es capaz de todo eso" (Lo que es Chile y lo que debe hacerse con Chile, 1879: 18).

El autor de las misivas fue un hombre de dilatada vida pública y profesional. Justiniano Sotomayor nació en Santiago en 1845. Se tituló de ingeniero en 1867 y de geógrafo al año siguiente. Se desempeñó como profesor de matemáticas del Liceo de Copiapó para, en 1873, comenzar a trabajar como gerente de la Compañía Corocoro de Bolivia, dedicada a la extracción de minerales. A poco andar, el gobierno chileno le encargó su representación en la nación altiplánica en calidad de cónsul. Declarada la Guerra del Pacífico, 
renunció a ambas actividades marchándose a Lebu para laborar a las órdenes de Maximiano Errázuriz. Fue estando nominalmente fuera del gobierno chileno que escribió a Daza. Dos años más tarde, se desplazó a Santiago para hacerse cargo de la gerencia de la Compañía de Gas. Tiempo después, en 1888, incursionó en la política siendo elegido diputado por Cauquenes representando al Partido Liberal. Ese mismo año fue llamado por el presidente José Manuel Balmaceda para ocupar la cartera de Hacienda, desempeñándose en esas funciones hasta junio de 1889, para luego ser nombrado director general de Obras Públicas, puesto en el que permaneció hasta el estallido de la Guerra Civil de 1891. Tras la caída de Balmaceda, volvió a Bolivia y se hizo cargo de la gerencia de la Compañía Minera de Oruro y nuevamente volvió a oficiar como cónsul chileno en ese país. Regresó a Chile en 1896 para otra vez ser nombrado director de Obras Públicas y en mayo ocupar la cartera de Hacienda, a la que renunció en junio de 1897 (Figueroa, 1931: 859). La muerte le sorprendió en Bélgica en julio de 1909.

Como se señaló en líneas precedentes, las dos cartas de Justiniano Sotomayor enviadas a Hilarión Daza en abril de 1879 fueron hechas publicar en la prensa a poco de llegadas a las manos del mandatario boliviano. En efecto, vieron la luz en El Comercio de Tacna. La transcripción aquí realizada, se realizó respecto de la reproducción de ellas hecha en El Constituyente de Copiapó del 20 de mayo de 1879, bajo el título "Correspondencia de Daza".

\section{Cartas de Justiniano Sotomayor a Hilarión Daza}

"Santiago, abril 8 de 1879.

Señor don Hilarión Daza.

La Paz.

Apreciado amigo:

Me encuentro aquí desde hace un mes, y usted no tendrá necesidad de que le diga por qué me he venido.

La ruptura de relaciones entre Bolivia y Chile me ha sido muy dolorosa porque siempre he sido de opinión que no debiera haber en la América del Sur países que cultivasen más estrechas relaciones de amistad.

El Perú por el contrario es el peor enemigo de Bolivia, es el que lo agobia bajo el peso de sus trabas aduaneras, el cancerbero de la libertad comercial, industrial y hasta cierto punto política de Bolivia.

Chile ha llevado a Bolivia industrias y capitales. Con este impulso la minería ha tomado allí un considerable impulso y esa actividad ha tenido que refluir sobre la agricultura y sobre la riqueza del país. 
Chile es el único país que puede librar a Bolivia del pesado yugo con que el Perú la oprime.

Chile es también la única nación que aliada a Bolivia puede darle lo que le falta para ser una grande nación, es decir, puertos propios y vías expeditas de comunicación.

¿Puede pensarse seriamente en Bolivia en buscar por Cobija y demás puertos de su litoral una salida para su comercio? Profundo error.

Los único puertos naturales de Bolivia son Arica, Ilo, Mollendo e Islay.

Aliada del Perú y haciendo la guerra a Chile, ¿qué sucederá a Bolivia si Chile es vencido? Que caerá en manos del Perú y gemirá como antes bajo el peso de sus gavetas. Y si Chile triunfase, ¿qué ganarían lo aliados? Bolivia vencedora o vencida quedará sin puertos y anulada como nación.

Por el contrario Bolivia unida a Chile, ¿no tendría la seguridad de vencer al Perú? ¿No tendría en su mano apoderarse de la calle de que carece?

Una cosa he notado aquí desde mi llegada. No hay odio alguno contra Bolivia, se han respetado los bienes y personas de los bolivianos, la guerra a Bolivia no ha conmovido al país salvo alguno que otro movimiento de tropas; parecíamos estar en paz. Pero llegó el momento de declarar la guerra al Perú y el país se levantó en masa, como un solo hombre, y todos han conocido que el Perú ha llenado la medida de sus intrigas, ingratitudes y deslealtades y solo se habla de castigarlo terriblemente.

Al Perú le haremos guerra a muerte. [A] Bolivia no podemos odiarla.

¿Por qué andamos tan descarriados haciendo guerras que no nos convienen y contrayendo alianzas que nos convienen menos aun?

¿Sería aún tiempo de poner las cosas en orden?

¿Por qué no?

Ahora o nunca debe pensar Bolivia en conquistar su rango de Nación, su verdadera independencia que por cierto no está en Antofagasta sino en Arica.

Después de esta guerra ya sería tarde. Chile vencedor no lo consentiría a menos de tener a Bolivia de su parte. El Perú vencedor le impondría la ley a Bolivia su aliada y a Chile su enemiga y Chile debilitado no podría ayudar a Bolivia aunque ésta se lo pidiera.

El hombre que de a Bolivia su independencia del Perú será más grande que Bolívar y que Sucre porque aquellos solo le dieron un simulacro de libertad y este se le daría real y verdadero. 
¿Estaba reservada a usted tan colosal empresa?

Su afectísimo amigo y S. S.

[Firmado] J. Sotomayor".

"Santiago, abril 11 de 1879.

Señor don Hilarión Daza

La Paz.

Con fecha 8 del corriente me he tomado la libertad de dirigirle una carta sometiéndole ciertas ideas que espero le hayan merecido alguna atención, porque no ha de tardar mucho en llegar el momento de que puedan ser llevadas al terreno de la práctica.

Usted habrá tenido ya alguna oportunidad de notar lo que valen sus aliados actuales, que después de conseguir su fin de poner en guerra a Chile con Bolivia y de gritar y hablar mucho, todavía nada han hecho en favor de ustedes, ni harán, ni podrían hacer, aunque lo quisieran.

Hace ya ocho días a la fecha que la escuadra chilena está bloqueando a Iquique, y la tan ponderada escuadra peruana no ha salido a proteger ese importante puerto, desentendiéndose así de dar combate a que nuestra escuadra la provoca.

Espero que al fin se resolverá a salir del Callao y que nuestra escuadra de buena cuenta de la peruana.

Dueños nosotros del mar, obligaremos al Perú a hacer la paz bajo las condiciones que Chile quiera imponerle y entonces quedará Bolivia imposibilitada para recuperar su antiguo litoral y aun para pensar en conquistar jamás a Tacna, Arica, llo y Moquegua que es y debe ser su sueño dorado de nación.

El Perú no tardará mucho en dar a Bolivia fundados motivos de queja, porque no le cumplirá ninguna de las promesas que le ha hecho.

No extrañe Usted que me interese por Bolivia y que desee verla unida a mi país estrechamente. He estado en Bolivia ocho años y tengo mi porvenir vinculado a una empresa radicada en ese país, la cual he formado en seis años de asiduo trabajo. Después de Chile, es Bolivia el país de más simpatías para mí.

Durante mi permanencia en Bolivia he expresado siempre mi parecer de que Bolivia no tiene mejor amigo que Chile, ni peor verdugo que el Perú. Este hace el papel de vampiro que chupa a Bolivia toda su 
sabia vital, mientras Chile, le ha llevado brazos, capitales e inteligencia para desarrollar su riqueza nacional.

El Perú oprime a Bolivia con sus leyes de tránsito o de aduanas y en Chile se ha visto con pena ese estado de cosas y se ha simpatizado con la aspiración de un noble país que lucha en vano por obtener vías propias para ponerse en relación con el resto del mundo.

Buscar esa solución por el Amazonas, por El Plata, o por Cobija o Mejillones son sus sueños, porque esas vías serán en todo caso mucho más caras que Tacna y Arica; aun cuando en esa se cebe la codicia del Perú.

Para Bolivia no ha salvación, no hay porvenir, no hay esperanza de progreso, mientras no sea dueña de llo y Moquegua - Tacna y Arica.

Imagínese Ud. a Bolivia en posesión de esos territorios. En muy poco tiempo una línea férrea uniría a Tacna con La Paz y el telégrafo lo pondría en contacto con el mundo entero. La industria y comercio tomarían un inmenso desarrollo. Bolivia vería incrementarse rápidamente sus rentas, efluir la inmigración, crecer su población; sus importantes productos agrícolas y mineros irían a competir con los de sus vecinos en los mercados del mundo. Bolivia podría tener marina de guerra y marina mercante. En vez de consumirse en disturbios y revoluciones internas emplearía su actividad en progresar y enriquecerse.

La posesión de Tacna y Arica sería para Bolivia la varita mágica que todo lo transformaría.

Bolivia, que encierra en su seno tantas o mayores riquezas que Chile y el Perú y a la que solamente faltan puertos propios en situación conveniente, llegaría en muy poco tiempo a competir con sus vecinas en población, rentas, riquezas y adelantos materiales de todo género.

La alianza con el Perú, la derrota de Chile ¿pueden darle algo parecido? ¿Tendría siquiera gloria?

¿La gloria no sería para el Perú, y los gastos y perjuicios de la guerra, no sería para Bolivia?

¿No quedaría Bolivia más oprimida que antes por el Perú y con menos probabilidades de salir jamás de su posición secundaria y avasallada? Y en caso de vencer Chile por mar (que es lo más seguro) a la escuadra peruana, ¿cómo podría Bolivia pensar en atacarnos en Antofagasta? Todo su valor y decisión, ¿no serían vencidos por el desierto antes de llegar a las manos?

El Perú que ha sido desleal con Chile y con Bolivia en repetidas ocasiones no tardará de dar a Usted algún motivo poderoso de queja que sirva de punto de partida para la alianza con Chile, la cual aquí 
no encontraría grandes dificultades para ser aceptada según el espíritu que ha podido observar en la generalidad del pueblo, es cual, si odia al Perú, ha tenido mas bien simpatías por Bolivia hasta la última emergencia que nos ha hecho romper relaciones.

Con gusto me impondré de su contestación que tenga a bien darme, para seguir trabajando por la difusión de mi idea, dado caso de ser ella favorable.

Su afectísimo amigo y S. S.- [Firmado] J. Sotomayor".

\title{
Referencias bibliográficas
}

\section{Fuentes primarias}

\author{
a) Publicaciones periódicas \\ El Constituyente, Copiapó, 1879.
}

b) Impresos

Ahumada, P. (1884). Guerra del Pacífico. Recopilación completa de todos los documentos oficiales, correspondencias y demás publicaciones referentes a la guerra que hadado a la luz la prensa de Chile, Perú y Bolivia. Conteniendo documentos inéditos de importancia. Vol. I., Valparaíso: Imprenta del Progreso.

Castagneto, P. (2014). Cartas de la Escuadra. La Campaña Naval de 1879 relatada por el corresponsal de "El Mercurio". Santiago: RIL.

Lo que es Chile y lo que debe hacerse con Chile (1879). La Paz: Imprenta de la Unión Americana.

Ochoa, J. (1899). Diario de la campaña del Ejército boliviano. Sucre: Tipografía y Librería Económica.

Orrego, A. (2009). José Francisco Vergara: Guerra del Pacífico y liberalismo. Valparaíso: Consejo Nacional de la Cultura y las Artes.

\section{Fuentes Secundarias}

\section{a) Artículos}

Rubilar, M. (2004). "Guerra y diplomacia: las relaciones chileno-colombianas durante la guerra y postguerra del Pacífico (1879-1886)", en Universum, $N^{\circ}$ 19, Vol. 1. Revisado en http://dx.doi.org/10.4067/S0718-23762004000100009. 
Tapia, C. (2016). "Política exterior ecuatoriana durante la guerra del Pacífico: un análisis desde la óptica de los equilibrios de poder en la región latinoamericana", en Revista Brasileira de Historia, Vol. 36, № 72, pp. 131-149.

\section{b) Libros}

Barros, M. (1970). Historia diplomática de Chile. Santiago: Editorial Andrés Bello.

Bulnes, G. (1955). Guerra del Pacífico. 3 Vols. Santiago: Editorial del Pacífico.

Cariola, C. y O. Sunkel (1983). Un siglo de historia económica de Chile entre 1830 y 1930: dos ensayos y una bibliografía. Madrid: Ediciones Cultura Hispánica.

Figueroa, V. (1931). Diccionario biográfico de Chile. Vol. V. Santiago: Establecimientos Gráficos Balcells \& Co.

González, S. (2008). La llave y el candado. El conflicto entre Perú y Chile por Tacna y Arica (1883-1929). Santiago: LOM, Universidad de Santiago de Chile.

Ríos, C. (1963). Chile y Bolivia definen sus fronteras. Santiago: Editorial Andrés Bello. 